The Journal of Performance and Mindfulness

Available open access at: https://www.performanceandmindfulness.org.uk/

Reviews, Reflections, Interviews

\title{
Improv, a Venue for Values: Teaching Kindness
}

\section{Patricia Ryan Madson}

Senior Lecturer Emerita, Department of Theater and Performance Studies, Roble Gym, 375 Santa Theresa St. Stanford University, Stanford, CA 94305, USA

\section{KEYWORDS}

Improvisation Training Acceptance

Ethics in the Classroom

Gratitude

\section{ABSTRACT}

The improvisation classroom is an ideal venue to teach the virtue of kindness. Using explicit games which foster a change of perspective instructors can both model and teach life lessons.
On a cool December night, the line outside the Noh Stage Theatre in San Francisco was long waiting to get in to see Awkward Dinner Party, an unusual long-form improvisation format with a three-person cast. The lady standing behind me struck up a conversation. She wanted to sing the praises of Lisa Rowland, one of the principals of the improv show and the creator of this format. 'She is really brilliant as a teacher and, more importantly, I admire her as a person. I mean, she is just so good, so kind and so positive. Lisa is a remarkable human being'. I nodded agreement, mentioning that she had been one of my students at Stanford. We concurred that we were both fans.

Lisa's improv training was nourished in the crucible of the Stanford Improvisers (SIMPS), a group I founded in 1991. They have the reputation of being the nicest group to play with'. I was always pleased and flattered by that appellation. More important than being funny was being kind, 
easy and thoughtful to play with. Yes, the SIMPS were the nicest group at any tournament. I believe that this way of being together as a group was fostered by their training. Students reported that these social qualities stuck outside the improv stage and continued into life after Stanford.

I see our work as improv teachers as offering the possibility to make fundamental changes in society, one improvisor at a time. We do this both by modelling the behaviours we want to teach as well as finding ways both direct and indirect to teach them within the rubric of improvisation. All teaching is value laden, so why not teach the virtues our society most needs through improvisation? Many of us are stuck in old patterns of reacting. Improv provides a canvas upon which we can teach people how to listen better, be kinder and more helpful to each other.

As a tool the games can be used to lift others up or cut each other down. If you study comedy, you'll soon discover that the quickest way to get a laugh is to put someone else down. 'Hey, fellow, that's a nice dog you've got there'... 'That's no dog, that's my wife' (a double put down). Everyone laughs and the scene goes nowhere. Improv philosophy turns this habit around. We learn to eschew the easy laugh that comes from blocking an offer and we learn the foundational principle of acceptance, agreement and building on the ideas of our partners.

Lisa Rowland wrote:

Given the lack of planning and structure in improv the performers must function without a safety net. On reflection I realize that while performers function without the safety net of a script or predetermined blocking, they have a much more powerful safety net, which is their partners. People form the safety net in improv. They won't let me fall. They are my reassurance. What happens on stage may be scary, but we're all facing it together. (private email, March, 2019)

There is a critical life lesson in the 
unpacking of 'without a net'. What we have on this planet is one another. There is no net or security blanket that our government can provide that is fail-safe. What is dependable, as Lisa wisely points out, is the reality of having other people in our lives: partners, family, friends, colleagues, even strangers who are there to help when help is needed. Anyone living through some crisis or natural disaster knows this. Rebecca Solnit's wonderful book, $A$ Paradise Built in Hell (2010) is a testament to this. She documents the extraordinary acts of kindness that emerged out of the aftermath of the 1905 San Francisco earthquake and fire. We step up for each other time and again. If there is any security in life it comes from our human connections. Improvisors take care of each other.

There are three ways to foster ethical training in the classroom. 1. The instructor models mindful listening, the acceptance of offers and building upon the ideas of her students. The instructor must be kind. 2. We teach games and exercises that illustrate sharing control and helping our partners. 3. When we discuss and debrief exercises, we point out how certain habits are counter to our goal of being great team players; e.g., while sarcasm may well elicit a laugh it is usually at someone's expense. I point out that sarcasm is poison and can chip away at trust.

A favourite warm-up game that I learned from Nat Tsolak, a member of the Applied Improv Network, is called 'Random Acts of Kindness Introductions'. We stand in a circle and improvise introductions to the person on our right with a little-known story of a random act of kindness that they've done: 'l'd like to introduce Mark. Very few people know that whenever he crosses a toll bridge, he pays for the car behind him'. Then Mark introduces Alice standing next to him: 'l'd like you to meet Alice. She gets up early on the weekends 
and goes down to the beach near her home carrying a bag and picks up trash and disposes of it'. This goes on until everyone is introduced. The net effect of this game is to allow everyone to create a random act that shows off their partner as a kind person. It always leaves a warm feeling for the group and allows for some creative expression.

When I teach Keith Johnstone's Status work, I spend the most time on learning strategies for raising the status of my partner. I've discovered that we are already experts in how to lower someone's status and raise our own. By examining the myriad ways we can lift others through word and deed we exercise our 'kindness muscles'. When we play these games (e.g., 'Go onstage and approach an actor sitting on a bench. Do or say something to raise their status') we quickly discover how often we are actually doing the opposite of this intention. Playing status games allows us to laugh at our mistakes. Johnstone's favourite example of this tilt is when someone gives him a compliment. 'Keith, I really liked your play that you gave me to read'. Johnstone replies: 'Oh, it's not really done yet and the second act needs work'. The net effect of this exchange is to put down or lower the status of the person giving the compliment. Whenever we deflect a compliment, we do this.

When we debrief a simple exercise such as 'Sound Ball' in which a circle of players throws and receives random sounds, we have an opportunity for a moral lesson. I've seen leaders emphasize innovation and 'coming up with a clever sound' as the point of this game. I point out that the most important part is receiving the sound or word. Put all of your attention - your mindfulness - onto being a skilful receiver of the ball (sound). Honour your partner's effort in sending it. Your partner is always right.

Thoughtful improv training models and teaches inclusivity. The instructor is 
called upon to welcome and celebrate diversity in all forms. This happens both through games and exercises that shift attention from self to other as well as by debriefs that point out the value of such shifts. Humility is at its core, and value driven teaching becomes a kind of mindfulness in action. An improv class taught in this way can be a place to build trust and safety.

Over time improv can turn a group of normal, selfish bozos into a team of agreeable, cooperative, resourceful bozos. Self-interest is normal. With improv games we can make interest in one's fellows into something that is attractive, productive and doable. But teaching the games alone without the ethical side-coaching misses the opportunity that improv offers. Teach values, not just games.

\section{References}

Applied Improvisation Network (AIN) http://www.appliedimprovisation.network
Awkward Dinner Party https://www.facebook.com/awkwarddinner party

Johnstone, Keith, (1979) IMPRO, Improvisation and the Theatre. London: Faber and Faber.

Madson, Patricia Ryan, (2005) Improv Wisdom: Don't Prepare, Just Show up. Bell Tower Books.

Reynolds, David, (1983) Naikan Psychotherapy: Meditation for SelfDevelopment. Chicago: University of Chicago Press.

Solnit, Rebecca, (2010), A Paradise Built in Hell: The Extraordinary Communities that Arise in Disaster. New York: Penguin Books. 